\section{Febrile Seizures and Mesial Temporal Sclerosis}

\author{
Shlomo Shinnar, M.D., Ph.D.
}

Departments of Neurology and Pediatrics, Comprehensive Epilepsy Management Center, Montefiore Medical Center, Albert Einstein College of Medicine, Bronx, New York

\section{Febrile Seizures and Mesial Temporal Sclerosis}

$\mathrm{O}$ ne of the most controversial issues in epilepsy research is whether prolonged febrile seizures cause mesial temporal sclerosis (MTS) and temporal lobe epilepsy (TLE). Retrospective studies from tertiary epilepsy centers report that many adults with intractable TLE have a history of prolonged or atypical febrile seizures in childhood. However, population-based studies have failed to confirm this association, as have prospective studies of febrile seizures (1). This review summarizes the current knowledge from epidemiologic, imaging, and animal studies regarding this controversial subject, and it attempts to define the issues that should be addressed in future research.

\section{Epidemiologic Data}

Data from large cohorts of children with febrile seizures indicate that in $2 \%$ to $10 \%$ of children who have febrile seizures, unprovoked seizures or epilepsy will subsequently develop (1-5). In most studies, the risk of developing epilepsy after simple febrile seizures is only mildly elevated compared with the risk for the general population (1-5). To the contrary, complex febrile seizures are clearly associated with an increased risk of subsequent epilepsy. Prolonged febrile seizures, particularly very prolonged febrile seizures and febrile status epilepticus (SE), are associated with a substantially elevated risk for future epilepsy (1-3).

However, not all children with febrile seizures in whom epilepsy develops will have TLE. Typically, in those patients

Address correspondence to: Shlomo Shinnar, Comprehensive Epilepsy Management Center, Montefiore Medical Center, 111 E 210th St., Bronx, NY 10467. E-mail: sshinnar@aol.com

Supported in part by grant 1 R01 NS43209 from National Institutes of Neurological Disorders and Stroke.

Epilepsy Currents, Vol. 3, No. 4 (July/August) 2003 pp. 115-118 Blackwell Publishing, Inc.

(c) American Epilepsy Society with generalized febrile seizures, generalized epilepsies will develop, whereas in those individuals with focal febrile seizures, focal epilepsies will develop $(1,2)$, suggesting that febrile seizures may be an age-specific expression of seizure susceptibility in patients with an underlying seizure diathesis $(1,2,6)$. The types of epilepsy that occur in children with prior febrile seizures are varied and not very different than those that occur in children without such a history $(1,7,8)$. In Japanese children, an increased incidence of febrile seizures is not associated with an increased incidence of epilepsy (9). Furthermore, in randomized clinical trials, drugs such as phenobarbital or diazepam, which reduced the risk of recurrent febrile seizures, do not alter the risk of subsequent epilepsy (10-12). The weight of the epidemiologic data argues against a causal association in the majority of cases.

Febrile SE, which is the extreme end of complex febrile seizures, accounts for approximately $5 \%$ of all febrile seizures (13) and for $25 \%$ of all pediatric SE (14). If febrile seizures cause MTS and TLE, then patients at highest risk should be those with febrile $S E$ (duration $\geqq 30 \mathrm{~min}$ ). However, the data from prospective outcome studies of febrile SE, unfortunately, are inconclusive. Studies of febrile $S E(1,2,13,15)$ all report a much higher risk of epilepsy, but they have not specifically addressed whether an increased risk of TLE occurs, and no imaging data are available on these cohorts, so that the incidence of MTS cannot be assessed.

\section{Limitations of Epidemiologic Studies}

Inherent limitations are found in the ability of epidemiologic studies to address the relation between prolonged febrile seizures and MTS or TLE. If TLE is used as the outcome, the latency period between febrile seizures and the subsequent development of recognizable TLE is quite long, averaging 8 to 11 years $(1,16,17)$. Recent data from the multicenter study of epilepsy surgery indicate that there may be an even longer latency period before epilepsy becomes intractable (18). The latency issue could be overcome by substituting anatomic MTS, which occurs more quickly, as the designated outcome; however, MTS has not yet been established as a valid surrogate for TLE.

Another serious limitation of epidemiologic studies in establishing a causal relation between febrile seizures and MTS or TLE is the relative rarity, at least in humans, of the target event (i.e., both febrile seizures and MTS and/or TLE). The various studies that examine the relation between prolonged febrile seizures and MTS report a mean duration of febrile seizure of 90 to 100 minutes in those patients with subsequent MTS 
$(1,19-21)$. Less than $1 \%$ of cases of febrile seizures are both focal and longer than 60 minutes $(13,22)$. As with prolonged seizures, acute injury and/or subsequent MTS do not occur in all cases. Therefore, the number of subjects needed to find an effect, with only epidemiologic techniques, is huge and well beyond the numbers seen in any of the published epidemiologic series thus far. Given the high frequency of prior febrile seizures in patients with epilepsy for whom the febrile seizures clearly are a marker for increased seizure susceptibility, it is not surprising that epidemiologic studies have not detected the relatively small number of cases of MTS and TLE in which a causal relation between prolonged febrile seizures and MTS or TLE actually exists.

\section{Imaging Data}

Magnetic resonance imaging (MRI) has demonstrated abnormalities in the hippocampus after prolonged febrile seizures $(1,21,23)$. The changes may be transient and, therefore, not detected, unless MRI is performed shortly after the prolonged seizure. MRI is requisite to the detection of chronic hippocampal injury, such as in MTS. Although hippocampal MRI abnormalities may be seen after prolonged febrile seizures, it is not clear how to predict whether the abnormality will be permanent. Nevertheless, the best available data for a causal relation between prolonged febrile seizures and MTS come from imaging studies.

The most interesting data to address the causal relation issue come from recent prospective studies of febrile SE that have imaged affected children within 72 hours of the seizure $(21,23)$. VanLandingham et al. (21) described 27 infants aged between 8 and 24 months who were imaged after prolonged febrile seizures. They reported acute hippocampal MRI abnormalities in four of the 15 infants with focal or lateralized prolonged febrile seizures and in none of the 12 infants with generalized prolonged febrile seizures. The mean seizure duration in those showing acute changes was 99 minutes, compared with 41 minutes in those with focal seizures and 46 minutes in those with generalized febrile seizures $(P<.05)$ who did not have acute imaging abnormalities. Notably, only those children whose seizures were both focal and prolonged had evidence of either acute changes or later MTS. It is difficult to distinguish which feature is most important, as the majority of very prolonged febrile seizures are focal (13). However, at least two other studies on the association between prolonged febrile seizures and MTS reported that the mean duration of the febrile seizure in cases with MTS was 90 to 100 minutes $(19,20)$.

The group of investigators at Duke University has enlarged and further researched the original cohort of 27 children studied by VanLandingham et al. (23). On careful reexamination, 30\% of MRIs done within 72 hours of the prolonged febrile seizures were abnormal on visual inspection by blinded readers, including those of four infants with severely abnormal scans. The most predictive abnormality in terms of subsequent MTS was an ab- normal hippocampal $\mathrm{T}_{2}$ signal. Of the eight children with prolonged febrile seizures who had two or more scans, four children had severe $T_{2}$ signal abnormalities on their initial MRIs. Three of these four patients went on to develop anatomic evidence of MTS, although, to date, in only one has TLE developed. None of the other children has subsequent anatomic evidence of MTS. The preliminary data also indicated that recovery from hippocampal atrophy can occur in some of these children.

\section{Limitations of Imaging Data}

It is tempting to use imaging as a surrogate for clinical outcome, but the approach should be used with caution. The data available so far demonstrate that very prolonged febrile seizures can result in acute hippocampal injury and subsequent MTS. They do not tell us how often this occurs or how often it results in subsequent medically refractory TLE. It is clear that not all cases of MTS are associated with refractory TLE $(24,25)$. It also is clear that only a minority of cases of MTS or TLE are associated with prior febrile seizures, whether causally or otherwise $(1,7,8,16,20,26)$. Despite the limitations, imaging studies offer the best opportunity to address directly the relation between febrile seizures and MTS in the human.

\section{Animal Data}

The recent development of good animal models of febrile seizures gives additional insight into the possible relation of prolonged febrile seizures and subsequent MTS and TLE (1). Recent animal data from Baram and colleagues $(1,27)$ suggest that prolonged febrile seizures may lead to long-lasting changes in the hippocampal circuits. In a rat model of prolonged febrile seizures, cytoskeletal changes in neurons were evident within 24 hours and persisted for several weeks without leading to cell loss. However, altered functional properties of these injured neurons were evident and persisted over the long term $(<60$ days) $(1,28)$. The changes were unique to prolonged febrile seizures and were not seen in other models of prolonged seizures in the immature brain. In the model developed by Baram and colleagues $(1,27)$, although transient anatomic changes occurred, no evidence of cell death was found after prolonged febrile seizures. Remarkably, although this research has produced convincing data for functional changes, seizure duration of 20 minutes or more was required. Seizures lasting 10 minutes or less were not associated with any anatomic or functional changes. The availability of animal models provides a new means of studying the pathophysiology of febrile seizures and their consequences.

\section{Other Questions}

Additional issues that should be addressed include the role of preexisting neurologic abnormalities, effects of genetic background, and possible associations with specific viral infections. 
The Role of Preexisting Abnormalities in Seizure Induced Injury

Whereas it is clear that seizure-induced injury can occur in humans, the necessary substrates have not been identified. The clinical (19-21) and animal (29) data suggest that children with preexisting brain abnormalities may be more prone both to having prolonged seizures and to seizure-induced injury. In the study of VanLandingham et al. (21), two of three children who demonstrated acute hippocampal changes that progressed to MTS had evidence of preexisting pathology. A high frequency of subtle cortical dysplasia $(17,30)$ or other preexisting hippocampal abnormalities exists in patients with evidence of MTS. Moreover, animal data indicate that rat pups with cortical dysplasias are more prone to seizure-induced damage (29). Further studies are needed to clarify whether preexisting MRI abnormalities are an independent risk factor for hippocampal injury in humans or if they simply predispose to prolonged and lateralized seizure activity, which then causes the damage.

\section{Genetics}

Accumulating evidence indicates that a genetic contribution may exist to susceptibility to febrile seizures, susceptibility to prolonged seizures, and even susceptibility to seizure-induced damage. It has long been known that a family history of febrile seizures is a major risk factor for febrile seizures in offspring (1). More recently, research demonstrated an underlying predisposition to prolonged seizures. Although children with a prolonged first febrile seizure are not at increased risk for another febrile seizure, should one occur, it is likely to be prolonged (13). The same is true in children with a first unprovoked, prolonged afebrile seizure (31). A clear genetic component to prolonged seizure was demonstrated in twin studies by Corey et al. (32) The researchers reported a risk of SE of 38\% (55\% when the co-twin also had a history of seizures) among the co-twins of monozygotic twins who experienced SE. The recent report of an association between a polymorphism at the interleukin- $1 \beta$ (IL-1 $\beta$ ) locus and MTS in patients with TLE suggests that genetic factors also may predispose to the development of MTS after a prolonged febrile seizure (33). IL- $1 \beta$ has been implicated in the mechanism of generating fever, in lowering the seizure threshold, and in prolonging seizures (1). However, in spite of all the tantalizing hints regarding possible genetic factors in the occurrence of febrile seizures and of seizure-induced injury, little is known about the precise genes involved or the mechanism by which their influence might be exerted. The genetic mechanisms involved in the susceptibility to febrile seizures, in general, and prolonged febrile seizures, in particular, as well as the genetic mechanisms responsible for predisposing to seizureinduced injury, each offer exciting avenues of future research.

\section{Role of Specific Pathogens}

Several lines of evidence demonstrate that specific viral pathogens, in particular, human herpes virus (HHV)-6 and HHV-7, may be implicated in the development of MTS after prolonged febrile seizures. Findings in the pediatric literature implicate HHV-6 and HHV-7 in up to half the cases of febrile seizures in children younger than 3 years $(34,35)$. Children with primary HHV infection are more likely to have prolonged, focal febrile seizures and to have postictal paralysis than are those patients with febrile seizures not occurring with HHV-6 infection. It remains unclear whether these viruses are associated with prolonged febrile seizures because of the high fevers that occur with them or whether the viruses are involved with the pathogenesis of seizure-induced damage, as the herpesviruses have the potential to be neurotropic (36). Further study of their precise role is needed.

\section{Future Studies}

Researchers now have the tools to address the long-standing controversy regarding the relation between prolonged febrile seizures and MTS. Animal studies will further elucidate the underlying mechanisms concerning the sequelae of febrile seizures and provide insights into potential approaches to prevent them. In the clinical arena, imaging studies combined with classic epidemiologic techniques offer an opportunity to answer questions regarding the relation between prolonged febrile seizures and subsequent MTS and TLE. Studies, such as those of VanLandingham et al. (21), which imaged children with prolonged febrile seizures, must be combined with long-term follow-up and with classification of the subsequent epilepsy by syndromes. Ultimately researchers will probably need to combine findings from epidemiologic methods, imaging techniques, and genetic analyses to untangle the numerous factors contributing to the mechanisms that underlie the relation between prolonged febrile seizures and subsequent MTS and TLE.

Ongoing, multicenter studies may answer some key clinical questions by prospectively examining large cohorts of children with febrile $S E$ ( $\geqq 30 \mathrm{~min}$ ), by using imaging within 72 hours of the event, and then following up the children for the development of MTS or any other type of clinical epilepsy. Key questions to be answered include the following: How often does seizure-induced damage occur? What are the risk factors? How often does MTS result? Although febrile seizures are the most common form of childhood seizures, given the need to examine very prolonged febrile seizures, no one center would have sufficient numbers to address this question prospectively. With the tools now available, large, multicenter research promises to have adequate power to provide more definitive answers to the controversial relation between febrile seizures and MTS and TLE. 


\section{References}

1. Baram TZ, Shinnar S, eds. Febrile Seizures. San Diego, CA: Academic Press, 2002.

2. Annegers JF, Hauser WA, Shirts SB, Kurland LT. Factors prognostic of unprovoked seizures after febrile convulsions. N Engl J Med 1987;316:493-498.

3. Berg AT, Shinnar S. Unprovoked seizures in children with febrile seizures: short term outcomes. Neurology 1996;47:562-568.

4. Nelson KB, Ellenberg JH. Predictors of epilepsy in children who have experienced febrile seizures. N Engl J Med 1976;295:10291033.

5. Verity CM, Golding J. Risk of epilepsy after febrile convulsions: a national cohort study. Br Med J 1991;303:1373-1376.

6. Shinnar S, Moshe SL. Age specificity of seizure expression in genetic epilepsies. In: Anderson VE, Hauser WA, Leppik IE, Noebels JL, Rich SS, eds. Genetic strategies in epilepsy research. New York: Raven Press, 1991:69-85

7. Berg AT, Shinnar S, Levy SR, Testa FM. Childhood-onset epilepsy with and without preceding febrile seizures. Neurology 1999;53:1742-1748.

8. Camfield CS, Camfield PR, Dooley JM, Gordon, K. What type of afebrile seizures are preceded by febrile seizures? A populationbased study of children. Dev Med Child Neurol 1994;36;887892.

9. Tsuboi T. Epidemiology of febrile and afebrile convulsions in children in Japan. Neurology 1984;34:175-181.

10. Knudsen FU, Paerregaard A, Andersen R, Andresen J. Long term outcome of prophylaxis for febrile convulsions. Arch Dis Child 1996;74:13-18.

11. Wolf SM, Forsythe A. Epilepsy and mental retardation following febrile seizures in childhood. Acta Paediatr Scand 1989;78:291295.

12. Berg AT, Shinnar S. Do seizures beget seizures? An assessment of the clinical evidence in humans. J Clin Neurophysiol 1997;14:102-110.

13. Berg AT, Shinnar S. Complex febrile seizures. Epilepsia 1996;37:126-133.

14. Shinnar S, Pellock JM, Moshe SL, Maytal J, O’Dell C, Driscoll SM, Alemany M, Newstoin D, DeLorenzo RJ. In whom does status epilepticus occur: age-related differences in children. Epilepsia 1997;38:907-914.

15. Verity CM, Ross EM, Golding J. Outcome of childhood status epilepticus and lengthy febrile convulsions: findings of national cohort study. Br Med J 1993;307:225-228.

16. French JA, Williamson PD, Thadani VM, Darcey TM, Mattson RH, Spencer SS, Spencer DD. Characteristics of medial temporal lobe epilepsy: I. Results of history and physical examination. Ann Neurol 1993:34:774-780.

17. Mathern GW, Pretorius JK, Babb TL. Influence of the type of initial precipitating injury and at what age it occurs on course and outcome in patients with temporal lobe seizures. J Neurosurg 1995;82:220-227.

18. Berg AT, Langfitt J, Shinnar S, Vickrey BG, Sperling MR, Walczak T, Bazil C, Pacia SV, Spencer SS. for the Multicenter Study of Epilepsy Surgery. How long does it take for partial epilepsy to become intractable? Neurology 2003;60:186-190.

19. Fernandez G, Effenberger O, Vinz B, Steinlein O, Elger CE, Dohring W, Heinze HJ. Hippocampal malformation as a cause of familial febrile convulsions and subsequent hippocampal sclerosis. Neurology 1998;50:909-917.
20. Maher J, McLachlan RS. Febrile convulsions: is seizure duration the most important predictor of temporal lobe epilepsy? Brain 1995;118:1521-1528.

21. VanLandingham KE, Heinz ER, Cavazos JE, Lewis DV. MRI evidence of hippocampal injury after prolonged, focal febrile convulsions. Ann Neurol 1998;43:413-426.

22. Shinnar S, Pellock JM, Berg AT, O’Dell C, Driscoll SM, Maytal J, Moshe SL, DeLorenzo RJ. Short term outcomes of children with febrile status epilepticus. Epilepsia 2001;42:47-53.

23. Lewis DV, Barboriak DP, MacFall JR, Provenzale JM, Mitchell TV, VanLandingham KE. Do prolonged febrile seizures produce medial temporal sclerosis? Hypotheses, MRI evidence and unanswered questions. Prog Brain Res 2002;135:263-278.

24. Kim WJ, Park SC, Lee SJ, Lee JH, Kim JY, Lee BI, Kim DI. The prognosis for control of seizures with medications in patients with MRI evidence for mesial temporal sclerosis. Epilepsia 1999;40:290-293.

25. Kobayashi E, Lopes-Cendes I, Guerreiro CAM, Sousa SC, Guerreiro MM, Cendes F. Seizure outcome and hippocampal atrophy in familial mesial temporal lobe epilepsy. Neurology 2001;56:166-172.

26. Abou-Khalil B, Andermann E, Andermann F, Olivier A, Quesney LF. Temporal lobe epilepsy after prolonged febrile convulsions: excellent outcome after surgical treatment. Epilepsia 1993;34:878883.

27. Toth Z, Yan XX, Haftoglou S, Ribak CE, Baram TZ. Seizureinduced neuronal injury: vulnerability to febrile seizures in immature rat model. J Neurosci 1998;18:4285-4294.

28. Dube C, Chen K, Eghbal-Ahmadi M, Brunson K, Soltesz I, Baram TZ. Prolonged febrile seizures in the immature rat model enhance hippocampal excitability long term. Ann. Neurol 2000;47:336344.

29. Germano IM, Zhang YF, Sperber E, Moshe S. Neuronal migration disorders increase susceptibility to hyperthermia induced seizures in developing rats. Epilepsia 1996;37:902-910.

30. Hardiman O, Burke T, Phillips J, Murphy S, O’Moore B, Staunton H, Farrell MA. Microdysgenesis in resected temporal neocortex: incidence and clinical significance in focal epilepsy. Neurology 1988;38:1041-1047.

31. Shinnar S, Berg AT, Moshe SL, Shinnar R. How long do newonset seizures in children last? Ann Neurol 2001;49:659-664.

32. Corey LA, Pellock JM, Boggs JG, Miller LL, DeLorenzo RJ. Evidence for a genetic predisposition for status epilepticus. Neurology 1998;50:558-560.

33. Kanemoto K, Kawasaki J, Miyamoto T, Obayashi H, Nishimura M. Interleukin (IL)-1 $\beta$, IL-1a, and IL-1 receptor antagonist gene polymorphisms in patients with temporal lobe epilepsy. Ann Neurol 2000;47:571-574.

34. Hall CB, Long CE, Schnabel KC, Caserta MT, Mclntyre KM, Costanzo MA, Knott A, Dewhurst S, Insel RA, Epstein LG. Human herpesvirus- 6 infection in children: a prospective study of complications and reactivation. N Engl J Med 1994;331:432438.

35. Caserta MT, Hall CB, Schnabel K, Long CE, D'Heron N. Primary human herpesvirus 7 infection: a comparison of human herpesvirus 7 and human herpesvirus 6 infections in children. J Pediatr 1998;133:386-389.

36. Wainwright MS, Martin PL, Morse RP, Lacaze M, Provenzale JM, Coleman RE, Morgan MA, Hulette C, Kurtzberg J, Bushnell C, Epstein L, Lewis DV. Human herpesvirus 6 limbic encephalitis after stem cell transplantation. Ann Neurol 2001;50:612-619. 